\title{
ASSESSMENT OF IDIOPATHIC OSTEOSCLEROSIS IN THE JAWS OF THE EGYPTIAN POPULATION USING CONE BEAM COMPUTED TOMOGRAPHY
}

\author{
Mohamed Khalifa Zayet* and Ahmed Ali Hassan**
}

\begin{abstract}
Purpose: Idiopathic osteosclerosis is a common radiopaque lesion without clear cause that affects the mandible and maxilla. This study was conducted to assess the prevalence of idiopathic osteosclerosis in the jaws among Egyptian population.

Subjects and Methods: 1100 CBCT scans were used to assess the prevalence, gender and age distribution, location, and size of idiopathic osteosclerosis.

Results: Idiopathic osteosclerosis was found in $16.7 \%$ of the cases with equal distribution in males and females patients, especially, in the third decade. Mandibular lesions were found in $95.7 \%$ of them, $52.7 \%$ in molar region and $29.9 \%$ in premolar region. The size ranged from $1.5-15.6 \mathrm{~mm}$.
\end{abstract}

Conclusion: Idiopathic osteosclerosis is not uncommon radiographic finding in Egyptian population with predilection to premolar-molar mandibular region.

KEYWORDS: Idiopathic Osteosclerosis, Cone Beam Computed Tomography, Egyptian

\section{INTRODUCTION}

Idiopathic osteosclerosis is the condition of localized increased ossification of bone without obvious cause $^{(1)}$. Synonyms of idiopathic osteosclerosis include enostosis, dense bone island, bone whorls, and bone eburnation ${ }^{(2)}$. On the clinical aspect, idiopathic osteosclerosis is usually asymptomatic and always being discovered incidentally on radiographs. While radiographically, idiopathic osteosclerosis is a radiopaque area that occurs more commonly in the mandible, it could appear in teeth bearing area or away from the teeth, it may have regular or irregular outline with no effect on surrounding dental or bony structures ${ }^{(3-5)}$. Furthermore, its size may range from a couple of millimeters to few centimeters ${ }^{(6,7)}$

The prevalence of such lesion does not lie in a certain range among different races. Moreover, its distribution in mandible or maxilla, presence in

* Ass. Professor of Oral and Maxillofacial Radiology, Faculty of Dentistry, Cairo University, Egypt

** Ass. Lecturer of Oral Radiology, Faculty of Dentistry, El-Fayoum University 
particular regions in any of them, or even around the teeth or away from them is not constant. Nevertheless, posterior region of the mandible is the common site for idiopathic osteosclerosis ${ }^{(8)}$. These variations in size, extension, location, and shape in addition to lack of guiding clinical signs or symptoms render its diagnosis not an easy task for some clinicians ${ }^{(9)}$.

Although panoramic radiography was considered for several decades ago and till now the main radiographic modality for examining the jaw bones. However, cone beam computed tomography (CBCT) is one of the most promising imaging modalities nowadays in the dental domain ${ }^{(10-12)}$. Its applications in dental and maxillofacial fields increase and grow progressively (13-16). CBCT has the merits of 3D imaging modalities over the plain modalities in addition to some merits over medical computed tomography; like lower radiation dose, smaller footprint, lower cost, higher spatial resolution, as well as accompanying interactive software $^{(17,18)}$.

The aim of this study was to determine the prevalence of idiopathic osteosclerosis as well as its distribution in the jaws in a sample of Egyptian population using CBCT scans.

\section{Subjects and Methods:}

This cross-sectional retrospective descriptive study was conducted on $1100 \mathrm{CBCT}$ scans that were taken for Egyptian patients in a private center in the period from November 2016 to October 2018. The scanned patients were 467 males and 633 females. The age of them ranged from eight to 82 years with average of 38.1 years. The scans were performed on i-CAT scanner (Imaging Sciences International Hatfield, PA, USA) with the following exposure parameters: $\mathrm{kVp}: 120, \mathrm{~mA}: 5$ exposure time: 7 sec. Segmental scans or scans for single arch were excluded. The scans were evaluated by two calibrated oral radiologists with 17 and eight year experience using i-CATvision software. Idiopathic osteosclerosis was considered if radiopaque area was found without obvious carious lesions or large restoration in the crowns of related teeth as well as lack of radiolucency between the radiopaque lesion and tooth apex. Also radiopacities with surrounding radiolucent rim were excluded. Radiopaque lesions that caused obvious abnormalities in the surrounding dental or bony structures were not counted as idiopathic osteosclerosis. Identification sessions were ceased after 45 minutes or occurrence of eye or mental fatigue. The identification was performed on CBCT reformatted panoramic display mode, the determination of exact size and extension was performed on coronal and sagittal oblique orthogonal cuts.

\section{RESULTS}

From all the 1100 scans, idiopathic osteosclerosis was diagnosed in 184 cases with percentage of $16.7 \%$. Most cases were found in the third decade with mean age 35.8 years. The youngest case was in 17 year patient, while the oldest was in 70 year patient. Females were affected more than males; the number of cases that found in females was 105 (57.1\%), while that of males was 79 cases $(42.9 \%)$ (Figure 1).

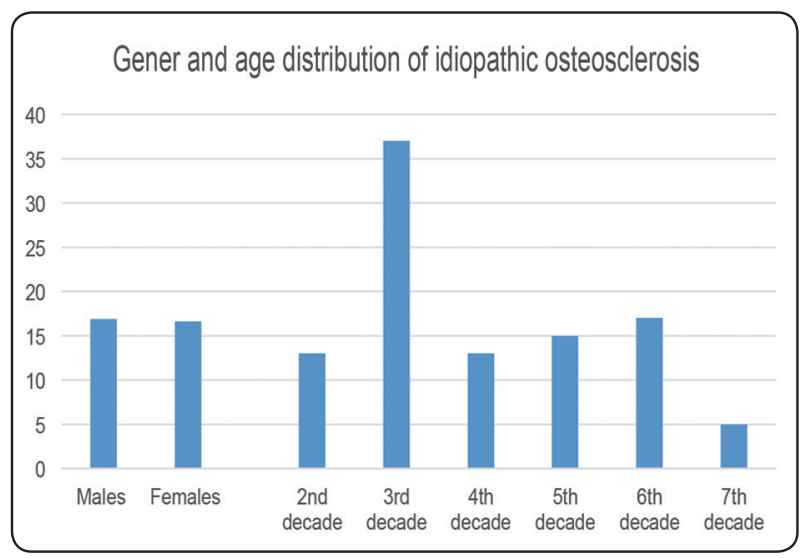

Fig. (1): Bar chart of percentages of gender and age distribution of idiopathic osteosclerosis. 
The difference between number and percentage of mandibular cases to those of maxillary cases was clear; 176 Cases $(95.7 \%)$ for the former and eight cases $(4.3 \%)$ for the later (Figure 2). Cases of teeth bearing area were 131 cases (71.2\%) while those of non-teeth bearing area were $53(28.8 \%)$. Regarding the region, molar region was the most common site (97 cases, 52.7\%), followed by premolar and canine region, 55 cases $(29.9 \%)$ and 16 cases $(8.7$ $\%)$ respectively. The incisor region was affected in four cases (2.2\%), and only 12 cases (6.5\%) were found in the ramus (Figure 3).

Cases confined within the cancellous bone were 51 cases $(27.7 \%)$, while those contacting the cortices were 133 Cases $(72.3 \%), 45$ Cases $(24.5 \%)$ contacting the buccal cortex and 88 Cases (47.8 $\%$ ) contacting the lingual cortex. The size of cases ranged from 2-15.6 $\mathrm{mm}$ in occluso-cervical height, $1.5-7.5 \mathrm{~mm}$ in mesio-distal width, and $1.7-8.4 \mathrm{~mm}$ in Bucco-lingual depth.
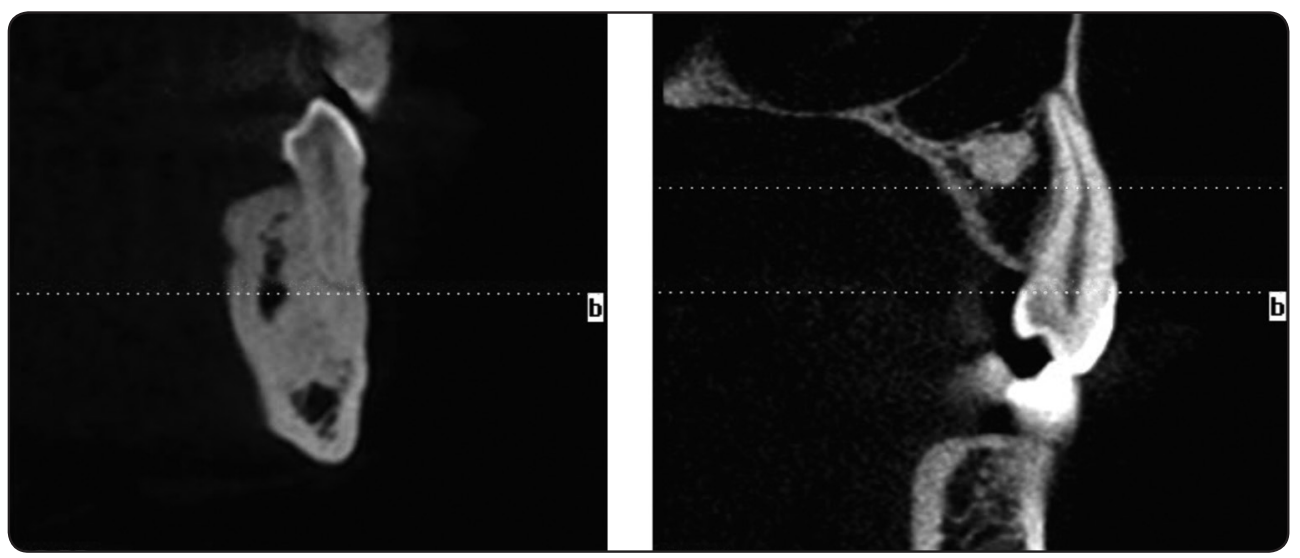

Fig. (2): Coronal CBCT images showing idiopathic osteosclerosis in the mandible (left) and maxilla (right)

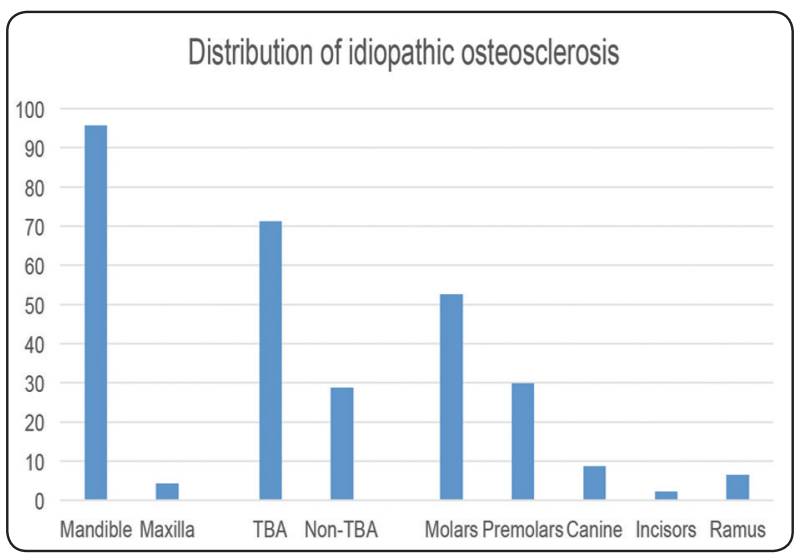

Fig. (3): Bar-chart showing the percentages of distribution of idiopathic osteosclerosis.

TBA: teeth bearing area

\section{DISCUSSION}

Although idiopathic osteosclerosis is one of the most common radiopacities of the mandible, but the studies about its characteristics in different populations are somehow not numerous enough $^{(1,4,5,8,19,20,21,22,23,24)}$

The prevalence of idiopathic osteosclerosis in Egyptian population in the current study (16.7\%) was higher than those of other studies investigating the same condition in other populations (2.8-7.5 $\%$ ), but this difference in prevalence could be partially attributed to difference among populations and partially due to that other studies depended on panoramic radiography which has inherent limitations that could hide small lesions, as well as those superimposed by anatomical shadows. 
Despite the number of cases found in females was larger than that in males, which means apparently that idiopathic osteosclerosis occurs more in females, but the reality is unlike that. As when considered the number of both genders in the sample, it showed that the percentage of occurrence in females $(16.6 \%)$ is equal to it in males $(16.9 \%)$, which is aligned with the results of other studies ${ }^{(4,}$ ${ }^{21,23)}$, but contradicted other studies which revealed more predilection in females ${ }^{(8,24)}$ and another study that revealed predilection to the other gender ${ }^{(22)}$.

The results of the current study showed that idiopathic osteosclerosis is common in the third decade with age range 17-70 years and mean of 35.8 years in agreement with many similar studies. However, there is no consensus on the mean age of disease occurrence or the range of age, which is dramatically influenced by the age distribution of the sample. Moreover, lack of symptoms may lead to late discovering of the condition.

The conclusion that mandible is more affected with idiopathic osteosclerosis than maxilla with dramatic difference was stated in almost previous studies conducted on panoramic images, but this finding could be partially due to fact that panoramic radiography reveals the mandible more obvious than the maxilla. However, the present study with utilizing of CBCT scans in order to overcome that limitation of panoramic radiography, revealed the same finding ( $95.7 \%$ in the mandible).

Teeth bearing area had the upper hand in cases with $71.7 \%$ of cases. Within the teeth bearing area, molar region was the commonest site $(52.7 \%)$ followed by premolars region (29.9\%). This was the same finding of some studies ${ }^{(5,24)}$, and on contrary to other ${ }^{(8,20,23)}$, but generally speaking, posterior region was affected much more than anterior region.

The size of the lesion should not be influencing factor in differential diagnosis of such condition, as in our study it ranged between $2-15.6 \mathrm{~mm}$ in one dimension, which was comparable to other studies that showed that size ${ }^{(4,20,24)}$, or even bigger $(5,6,25,26)$. The essential point is lack of clinical signs and symptoms such as pain, numbness, or swelling as well as absence of radiographic features like bone expansion, root resorption, loss of lamina dura, or displacement of mandibular canal.

\section{CONCLUSIONS}

Idiopathic osteosclerosis is a common radiopaque radiographic finding in Egyptian population with predilection to posterior region of the mandible and no sex predilection.

\section{REFERENCES}

1. Geist JR, Katz JO. The frequency and distribution of idiopathic osteosclerosis. Oral Surg Oral Med Oral Pathol. 1990 Mar;69 (3):388-93

2. Goaz PW, Wood NK. Differnential Diagnosis of Oral and Maxillofacial Lesions. $3^{\text {rd }}$ ed. 1997 Elsevier Mosby

3. Yonetsu K, Yuasa K, Kanda S. Idiopathic osteosclerosis of the jaws: panoramic radiographic and computed tomographic findings. Oral Surg Oral Med Oral Pathol Oral Radiol Endod. 1997 Apr;83(4):517-21.

4. Sisman Y, Ertas ET, Ertas H, Sekerci AE. The frequency and distribution of idiopathic osteosclerosis of the jaw. Eur J Dent. 2011 Aug;5(4):409-14.

5. Ledesma-Montes C, Jiménez-Farfán MD, HernándezGuerrero JC. Idiopathic osteosclerosis in the maxillomandibular area. Radiol Med. 2019 Jan;124(1):27-33.

6. Kawai T, Murakami S, Kishino M, Sakuda M. Gigantic dense bone island of the jaw. Oral Surg Oral Med Oral Pathol Oral Radiol Endod. 1996 Jul;82(1):108-15.

7. Misirlioglu M, Nalcaci R, Adisen MZ, Yilmaz S. The evaluation of idiopathic osteosclerosis on panoramic radiographs with an investigation of lesion's relationship with mandibular canal by using cross-sectional cone-beam computed tomography images. Journal of Oral and Maxillofacial Radiology. 2013 Aug:1(2):48-54

8. Moshfeghi M, Azimi F, Anvari M. Radiologic assessment and frequency of idiopathic osteosclerosis of jawbones: an interpopulation comparison. Acta Radiol. 2014 Dec;55(10):1239-44. 
9. Damm DD. Oral diagnosis. Mandibular radiopacities. Idiopathic osteosclerosis. Gen Dent. 2007 Nov-Dec;55(6): 591,595 .

10. Carter JB, Stone JD, Clark RS, Mercer JE. Applications of Cone-Beam Computed Tomography in Oral and Maxillofacial Surgery: An Overview of Published Indications and Clinical Usage in United States Academic Centers and Oral and Maxillofacial Surgery Practices. J Oral Maxillofac Surg. 2016 Apr;74(4):668-79.

11. Kawai T, Sato I, Asaumi R, Yosue T. Cone-beam computed tomography and anatomical observations of normal variants in the mandible: variant dentists should recognize. Oral Radiol. 2018 Sep;34(3):189-198.

12. Santos AA, Yamamoto-Silva FP, Torres EM, ValladaresNeto J, Figueiredo PTS, Leite AF, Silva MAG. Contribution of cone-beam computed tomography in the decision of surgical management for bone lesions of the maxillofacial region. J Craniomaxillofac Surg. 2019 Jan;47(1):87-92.

13. Scarfe WC, Azevedo B, Toghyani S, Farman AG. Cone Beam Computed Tomographic imaging in orthodontics. Aust Dent J. 2017 Mar;62 Suppl 1:33-50.

14. Venkatesh E, Elluru SV. Cone beam computed tomography: basics and applications in dentistry. J Istanb Univ Fac Dent. 2017 Dec 2;51(3 Suppl 1):S102-S121.

15. Morton D, Phasuk K, Polido WD, Lin WS. Consideration for Contemporary Implant Surgery. Dent Clin North Am. 2019 Apr;63(2):309-29.

16. Patel S, Brown J, Pimental T, Kelly R, Abella F, Durack C. Cone Beam Computed Tomography in Endodontics- a review of the literature. Int Endod J. 2019 Mar 14.

17. Scarfe WC, Farman AG. What is cone-beam CT and how does it work? Dent Clin North Am. 2008 Oct;52(4): 707-30
18. Angelopoulos C, Scarfe WC, Farman AG. A comparison of maxillofacial CBCT and medical CT. Atlas Oral Maxillofac Surg Clin North Am. 2012 Mar;20(1):1-17.

19. Kawai T, Hirakuma H, Murakami S, Fuchihata H. Radiographic investigation of idiopathic osteosclerosis of the jaws in Japanese dental outpatients. Oral Surg Oral Med Oral Pathol. 1992 Aug; 74(2):237-42.

20. MacDonald-Jankowski DS. Idiopathic osteosclerosis in the jaws of Britons and of the Hong Kong Chinese: radiology and systematic review. Dentomaxillofac Radiol. 1999 Nov;28(6):357-63. Review.

21. Verzak Z, Celap B, Modrić VE, Sorić P, Karlović Z. The prevalence of idiopathic osteosclerosis and condensing osteitis in Zagreb population. Acta Clin Croat. 2012 Dec;51(4):573-7.

22. Tolentino Ede S, Gusmão PH, Cardia GS, Tolentino Lde S, Iwaki LC, Amoroso-Silva PA. Idiopathic Osteosclerosis of the Jaw in a Brazilian Population: a Retrospective Study. Acta Stomatol Croat. 2014 Sep;48(3):183-92.

23. Naser AZ, Roshanzamir N. Prevalence of idiopathic osteosclerosis in an Iranian population. Indian J Dent Res. 2016 Sep-Oct;27(5):544-46.

24. Fuentes R, Arias A, Astete N, Farfán C, Garay I, Dias F. Prevalence and morphometric analysis of idiopathic osteosclerosis in a Chilean population. Folia Morphol (Warsz). 2018;77(2):272-8.

25. Mariani GC, Favaretti F, Lamazza L, DE Biase A. Dense bone island of the jaw: a case report. Oral Implantol (Rome). 2008 Jul;1(2):87-90.

26. Ledesma-Montes C, Jiménez-Farfán MD, HernándezGuerrero JC. Maxillomandibular giant osteosclerotic lesions. J Appl Oral Sci. 2018 Jun 18;26:e20170535. 